\title{
Climate change skepticism among adolescents
}

\author{
Maria Ojala \\ Örebro University \\ maria.ojala@oru.se
}

Accepted version of an article published in Journal of Youth Studies

The Version of Record of this manuscript has been published and is available in Journal of Youth Studies, 24 Mar 2015, http://www.tandfonline.com/, https://doi.org/10.1080/13676261.2015.1020927

\section{Acknowledgment}

This study was made possible by access to data from the Political Socialization Program, a longitudinal research program at YeS (Youth \& Society) at Örebro University, Sweden. Those responsible for the planning, implementation, and financing of the collection of data were professors Erik Amnå, Mats Ekström, Margaret Kerr and Håkan Stattin. The data collection was supported by grants from Riksbankens Jubileumsfond. The analysis of the data and the writing of the article were sponsored by a grant to the author from the Swedish Research Council Formas. 


\begin{abstract}
Young people relate to one of the most serious social problems, global climate change, in different ways. This study focuses on adolescents (Time 1: mean age $=16.6$ years) who deemphasize the seriousness of this problem. Hierarchical regression analyses were performed to investigate what factors predict climate skepticism cross-sectionally and what factors predict climate skepticism one year later. Two waves of data were collected (Time 1: $\mathrm{n}=870$; Time 2: $\mathrm{n}=684$ ). Factors important for explaining skepticism among adults (values, knowledge, conservative political orientation, gender, media use), a cluster of variables related to societal powerlessness (distrust, disinterest in societal issues, low environmental efficacy, low tolerance toward immigrants), and descriptive social norms (social influence from parents and peers) were included in the study. With the exception of media use in crosssectional analyses, and of media use and a conservative political orientation in bivariate longitudinal analyses, all of these factors were significantly associated with skepticism. However, only perceiving parents as having climate skeptical attitudes and low tolerance toward immigrants predicted an increase in climate change skepticism over the one-year period. Results are discussed in relation to earlier studies about climate change skepticism and socialization theories. Implications for climate change education are also discussed.
\end{abstract}

Keywords: descriptive social norms; values; tolerance toward immigrant; environmental efficacy; youth; climate change education 


\section{Climate change skepticism among adolescents}

\section{Introduction}

Climate change is one of the most pressing global concerns facing humanity today. Although there is a fairly widespread scientific consensus that the problem is serious and to a large extent induced by humans (see Brysse et al. 2013; IPCC 2007, 2013; Royal Society 2010), there is still quite a large proportion of people in different countries who are skeptical and who deny the seriousness of the climate threat (Davidson and Haan 2012; Eurobarometer 2009; Jackman 2009; Poortinga et al. 2011; Smith and Leiserowitz 2012; Whitmarsh 2011). Research has also identified sub-groups among adolescents who de-emphasize the seriousness of climate change (Klöckner, Beisenkamp and Hallmann 2010; Ojala 2012a, 2012b, 2012c, 2013). Because adolescence is the age when people are supposed to learn about climate change in school and because the young generation are the future leaders of society, one could argue that it is especially important to find out what factors underlie climate change skepticism in this age group. In order to reach this sub-group, educators and other adults could gain from getting a better insight into these factors.

There are rather numerous studies about young people’s worries concerning environmental problems (see for example Antilla et al. 2000; Ojala 2005) and about young people’s environmental engagement (Bynner, Romney and Emler 2003; Ostman 2014; Strandbu and Skogen 2000; Wilson and Shell 2010). However, few studies have focused specifically on climate change, and none has tried to explain why some young people do not take this problem seriously. Climate change skepticism could be seen as a form of political statement where some young people actively resist the low carbon subjectivities of today. However, it could also be a more passive response, indicating low confidence and low efficacy when it comes to societal issues. The objective of this study was to use a 
questionnaire study to investigate factors that predict climate change skepticism and their relative importance in doing so, cross-sectionally and over a one-year period, among a group of Swedish late adolescents. The study takes account of factors important for explaining climate skepticism among adults but also factors that have been shown to be vital when it comes to young people’s political socialization and environmental engagement.

\section{The concept of climate change skepticism}

In the present study I take account of Rahmstorf's (2004) view of climate change skepticism as consisting of three different dimensions: (1) Trend skepticism, which is about denying altogether that there is a problem with rising global temperatures; (2) Attribution skepticism, which is about denying that climate change is caused by humans to a large extent; and (3) Impact skepticism, which is about doubting that the future negative effects of climate change will be as powerful as many researchers claim. In an empirical study of the UK population, Poortinga and colleagues (2011) found that these three dimensions were closely related to each other among adults, although impact skepticism was more common than the other two dimensions. Thus, these three dimensions will be captured by one item each in the present questionnaire, and they are expected to fall into one coherent and reliable scale that will be called climate change skepticism.

\section{Knowledge and media attention as possible explanatory factors}

A traditional way of looking at aspects that hinder constructive and scientifically based action on environmental issues is that people lack knowledge about the issue at hand, and if only the right scientific facts are presented, in a way that people can understand, acceptance will ensue. However, this view is too simplistic, because, for example, worldviews and values seem to be more important than scientific knowledge when it comes to climate change perception (Kahan et al. 2012). This does not mean that knowledge is irrelevant (Engels et al. 
2013; Ojala 2013). Knowledge is far from the only explanatory factor, however, and it does not appear to be the most important one in influencing perceptions about climate change.

One source of information about the climate problem, perhaps the most important one for adults who are not in school, is the media. Media researchers claim that a common media norm is, on the one hand, to stress the importance of objectivity and balance between different viewpoints and, on the other hand, to emphasize drama, with diverging viewpoints being pitted against each other. This media norm is argued to influence people's perception of climate change in such a way that scientific uncertainty is exaggerated and the scientific near consensus is downplayed (see Boykoff and Boykoff 2004; Poortinga et al. 2011; Whitmarsh 2011). Thus, media use among the young could be positively related to climate skepticism. Other researchers argue instead that in more environmentally oriented countries media use could be related to better knowledge about climate change and hence lead to less skepticism about the seriousness of the problem (see Engels et al. 2013; Islam, Barnes and Toma 2013). In the present study I will include measures of both subjective knowledge and media use, as possible predictors.

\section{Gender and climate change skepticism}

One of the most consistent findings when it comes to explaining climate skepticism among adults is that men are more inclined than women to de-emphasize the seriousness of global climate change (Carlsson-Kanyama and Hörnsten Friberg 2012; Davidson and Haan 2012; McCright and Dunlap 2011; Poortinga et al. 2011; Whitmarsh 2011). These results could perhaps be explained by the fact that men, and especially older men, compared with women, have more to gain from preserving the present societal order and more to lose if major changes are carried out to adapt society to the reality of climate change (Feygina, Jost and Goldsmith 2010). 
Whether these gender differences are also present among adolescents is an interesting issue to explore. Thus, in accordance with the studies mentioned above I will include gender as a possible explanatory factor in the present study.

\section{The importance of values, worldviews, and political orientation}

Several studies have found that thinking environmental values are important is associated with a lower degree of climate skepticism (Engels et al. 2013; Islam et al. 2013; Leiserowitz et al. 2013; Poortinga et al. 2011; Whitmarsh 2011). It has also been found that people who are politically conservative are more likely to de-emphasize the seriousness of the climate problem than those who are less conservative in their political orientation (Carlsson-Kanyama and Hörnsten Friberg 2012; Davidson and Haan 2012; Lynn Guber 2013; Levinston and Walker 2012; McCright and Dunlap 2011). Some researchers have also argued that selfenhancement values such as egocentrism and hedonism might go together with skeptical attitudes toward climate change, however the empirical support for this is less convincing (see for instance Islam et al. 2013).

Why then are values and political orientations important? One explanation can be found in the 'identity protective theory' created by Kahan and colleagues (2007) in the context of risk perception. This theory integrates cognitive and cultural social-psychology theories on worldviews. It claims that people are inclined to take in information that supports their cultural worldviews and their social identity while ignoring or denying information that threatens their social identity and thereby the self-esteem achieved by belonging to a certain community or cultural group. Another closely related theory discusses system justification tendencies, proposing that by denying the seriousness of climate change, conservative, older, white men are defending their position of power in society (see Fegynia et al. 2010, McCright and Dunlap 2011). It is argued that taking this problem seriously would imply great changes to the present societal structure and thereby threaten the status quo of this group. 
To summarize, a number of different theories exist that try to explain why values and political orientations have an influence on skeptical attitudes toward climate change. However, these theories were developed in relation to an adult population, and one cannot be certain that values play an equally important role among adolescents. In this study, I will include measures of environmental and hedonistic/egoistic values, as well as measures of a conservative political orientation, in this case whether one sympathizes with the youth branches of the largest Swedish conservative party, 'Moderaterna,' and the next largest conservative party, ‘Sverigedemokraterna’. A Swedish study on local politicians’ attitudes toward climate change found that those who belonged to 'Sverigedemokraterna' were especially likely to embrace climate skeptical attitudes (Carlsson-Kanyama and Hörnsten Friberg 2012).

\section{Distrust, disinterest, environmental efficacy and tolerance toward immigrants}

Somewhat contrary to the theories mentioned above, that the most powerful members of society are de-emphasizing the climate threat to protect their status quo, other researchers argue that groups that feel threatened and marginalized in our globalized society are more inclined to hold views and values opposite to those of the liberal political elite (Holmberg 2007; Oscarsson and Holmberg 2008; Skogen 1999; Strandbu and Skogen 2000). For instance, they value anti-immigrant and anti-women attitudes, and sometimes also strong antienvironmental attitudes, to a high degree, at least in countries where the elite embraces environmental attitudes. In accordance with this view, Skogen (1999), in a study of Norwegian youth, identified a group consisting mainly of boys from the manual working class who exhibited strong anti-environmental and anti-immigrant attitudes. This is a group deeply rooted in the material production-oriented culture that in western countries is being challenged both by the globalization process and by the social reorientation that many believe is necessary if we are to solve the climate problem. In addition, Bynner and colleagues (2003) 
found a significant positive relation between environmentalism and tolerance toward immigrants and gender equality in a group of British youth, giving further support to a connection between attitudes toward the environment and tolerance.

Furthermore, a recent Swedish study showed that political distrust was an independent predictor of anti-environmental attitudes among adults (Harring and Jaegers 2013). In addition, an Australian qualitative study demonstrated that adults who deny the reality and seriousness of climate change were also inclined to evince a low level of trust in societal institutions (Hobson and Niemeyer 2013). Based on these studies it could be the case that low trust in political institutions can explain climate skeptical attitudes in addition to value orientations and political preferences among young people. This could be especially true in Sweden, which is considered to be a relatively environmentally friendly country where members of the elite often embrace environmental values, at least rhetorically (Holmberg, Weibull and Oscarsson 2011).

Another related but slightly different concept is interest in politics. Disinterest in politics is seen as being more passive in character in comparison with distrust in political institutions, which is considered to be a more critical and active stance towards societal issues (see Abdelzadeh and Ekman, 2012). In this regard, two studies of young people in Sweden have shown that a lack of interest in climate change as a societal problem in factor analyses seems to go together with traditional arguments against the dangers of climate change, such as that the problem is exaggerated (Ojala 2012b, 2013). In addition, Engels and colleagues found that political engagement among a group of German adults was negatively related to climate skepticism (Engels et al. 2013).

Another factor that could perhaps influence climate skepticism is whether or not the young people feel personally able to influence environmental issues, i.e., if they are high or low regarding perceived environmental efficacy. In cross-sectional studies of young people it 
has been found that the tendency to de-emphasize the climate threat is negatively related to environmental efficacy (Ojala 2012b, 2013). Young people who feel powerless when it comes to influencing environmental issues in general perhaps cope with this feeling by denying that threats such as climate change exist. This has not, however, been tested in a longitudinal context. Taking into consideration the studies mentioned above, the present study also includes measures of distrust in societal institutions, disinterest in political and societal issues, environmental efficacy, and tolerance toward immigrants.

\section{Social influence - descriptive social norms}

Studies about pro-environmental action and about political socialization among young people often focus on social influence as an important factor in explaining attitudes and actions. This approach diverges from the value approach in that it sees values as existing within the person, and therefore being a part of that person's identity, while social influence is seen as external to the individual and also to some extent as being a precursor of values (Biel, Fransson and Dahlstrand 1997; Schwartz 1977). Hence, it could be argued that measures of social influence are especially important to include in studies on young people’s views of climate change, because values and a political outlook are perhaps not yet wholly integrated into the person at this age.

When it comes to young people, the most important socialization agents are said to be their parents (Maccoby 2007). Through close interaction and communication in the family, children perceive what values, norms, and actions are important to their parents. According to Bandura’s social learning theory, parents can be seen as social role models for their children (Bandura 1977). The parents' actions, views, and attitudes become a sort of descriptive social norm for how one should think and act (see also Thøgersen 2006). Descriptive social norms concern perceptions of what important others do or think, and have been found to be very important when it comes to explaining pro-environmental behavior (Cialdini 2007; Nolan et 
al. 2008). Descriptive social norms are subjective in the sense that it is the person's own judgment of what important others think, feel, or do that has the most influence, not what these important others actually think or do. Thus, in a sense young people are active in their own socialization.

In addition, researchers in the field of political socialization point out that during adolescence social influence from parents decreases and peer influence becomes more important instead (Amnå et al. 2009; Dostie-Goulet 2009; Gordon and Taft 2011). Through talking and communicating with peers, young people adapt to each other's value orientations, in order to be liked and accepted in the peer group (Dostie-Goulet 2009). However, social influence has not been studied in relation to climate skepticism. Therefore, measures of young people’s views of their parents’ and peers’ climate skeptical attitudes, i.e., descriptive social norms in relation to parents and friends, will be included in this study.

\section{Aim of the study}

The aim of this study was to investigate what factors are significantly related to, and predict, climate change skepticisms among a group of late adolescents. The study first examines whether some well-known predictors of climate skepticism among adults - gender, media use, environmental values, hedonistic/egoistic values, a conservative political orientation - also are significantly related to this concept among a group of late adolescents living in Sweden. These are included in a first step in a hierarchical regression analysis. The study then focuses on a cluster of variables related to powerlessness concerning societal issues - distrust in institutions, disinterest in political and societal issues, low environmental efficacy, and low tolerance toward immigrants - as possible explanatory factors. These are inserted in a second step in the regression analysis. The study further explores whether social influence from parents and peers, i.e., descriptive social norms, have significant associations 
with climate skeptical views in this specific age group. These factors are included in a third, and final step, in the hierarchical regression analyses in order to investigate whether they explain skepticism when controlling for the other predictors.

In addition to looking at cross-sectional relations, an important aim has been to investigate whether these factors have significant relations to, and predict, climate skeptical attitudes over a one-year period. The reasons for including a longitudinal perspective in the study are threefold (see Lynn 2009): (1) By doing so, it is possible to capture stability or instability in climate change skeptical attitudes among young people. If there is great stability in attitudes over a one-year period, this indicates that these attitudes are not only erratic momentary views (see Scott 2000 for a critique of this view of young people), but more stable components of young people’s attitude structures. (2) In addition, a longitudinal design enables the researcher to explain possible change in attitudes over time. (3) Finally, even though causality in a strict sense cannot be captured with a longitudinal design (the third variable problem), if an independent variable is measured before a dependent variable in time, the researcher can argue with a higher degree of certainty than in cross-sectional studies that it is this independent variable that influences the dependent variable, and not the other way around.

\section{Method}

\section{Participants and procedure}

The data is taken from a longitudinal questionnaire study conducted at three senior high schools in a city in central Sweden with a population of about 135,000. According to national statistics, in 2010 this city was comparable to the Swedish average for unemployment rate, percentage of immigrants, and annual mean income (Statistics Sweden 2010). All tenth graders at the three schools were asked to participate in the study. The schools were selected 
to attain a representative distribution with respect to socioeconomic factors, and included both vocational and college-preparatory classes.

In the first wave of data collection carried out in the spring of 2010 (T1), 870 individuals answered the questionnaire, which yields a participation rate of $84 \%$ (49\% boys and $51 \%$ girls; mean age=16.6, $\mathrm{SD}=.72$ ). In the second wave, which took place one year later in the spring of 2011 (T2), 684 of the young people who participated in the first wave answered the questionnaire ( $50 \%$ boys and $50 \%$ girls; mean age $=17.4, \mathrm{SD}=.66$ ). Thus, between the two waves 186 participants dropped out of the study. The young people who participated at both time-points and those who participated only at T1 were not significantly different from each other on the dependent variable, i.e., climate skepticism, and most of the independent variables at Time 1 (p’s > .05). The only exception was influence from parents, where the participants who dropped out from $\mathrm{T} 1$ to $\mathrm{T} 2 \mathrm{had}$ a significantly higher mean $(\mathrm{M}=2.34)$ than those who participated at both time points $(\mathrm{M}=2.18)(\mathrm{p}<.05), \mathrm{t}(-2.23)=\mathrm{p}<.05$.

At both time points the young people filled out the questionnaires during regular school hours and were guaranteed anonymity. Participation was voluntary. Trained research assistants distributed the questionnaire and teachers were not present. Each participating class was paid approximately 100 Euro for collective use. The design of the longitudinal study was approved by a regional ethical board.

\section{Measures}

Climate change skepticism at T1 and T2 was captured by three items: 'I doubt that there is a global warming going on' (trend skepticism), 'I doubt that climate change is as big a problem as some researchers claim’ (impact skepticism), 'I doubt that climate change is caused by human emissions’ (attribution skepticism). In response to the question: 'To what extent do these statements correspond to how you think?' respondents rated each item on a 5point scale: 'Doesn’t apply at all = 1,' 'Doesn’t apply so well = 2,' 'Kind of applies = 3,' 
‘Applies quite well = 4,' 'Applies perfectly = 5.' Two principal component analyses were conducted in order to find out if the scale was unidimensional at both time points. The results of these analyses show that this was indeed the case; i.e., in both cases only one factor was extracted with an eigenvalue greater than one. Thus, by taking the mean of the three items, an aggregated scale of climate change skepticism was developed. The Cronbach's alpha of the scale at $\mathrm{T} 1$ was $.83(\mathrm{M}=2.08, \mathrm{SD}=1.03)$ and at $\mathrm{T} 2$ it was $.85(\mathrm{M}=1.94, \mathrm{SD}=.97)$.

Subjective knowledge was captured by one question where the young people indicated how much knowledge they perceived themselves to have about societal issues like climate change, politics, and international news. The participants chose from among five answers: 'Yes, I have better knowledge of these issues than friends of my own age (5),' 'Yes, I have a little better knowledge of these issues than friends of my own age (4),' 'Overall, I have about the same amount of knowledge about these issues as friends of my own age (3),' 'No, I have less knowledge than friends of my own age (2),' and 'No, I have much less knowledge than friends of my own age (1)' $(\mathrm{M}=3.07, \mathrm{SD}=.94)$.

Media use was measured with a scale revised from Livingstone and Markham (2008). The scale consisted of the stem question: 'How often do you get acquainted with the news in the following media?’ Thereafter four items followed: 'Read the morning or evening newspaper (in paper format),' 'listen to the news on the radio,' 'watch the news on TV,' 'use internet to check on the news.' Each item was followed by the response alternatives: 'at least five days a week (5),' '3 to 4 days a week (4),' '1 to 2 days a week (3),' 'more seldom (2),' ‘never (1)’ $(\mathrm{M}=2.85, \mathrm{SD}=.82)$. The Cronbach’s alpha reliability was .63

Environmental values was measured with three items taken from the biospheric value scale created by de Groot and Steg (2008) about the importance of respecting nature, preventing pollution, and protecting the environment. Each item was followed by a 5-point 
scale ranging from 'not at all important (1)' to 'very important (5)' $(\mathrm{M}=3.74, \mathrm{SD}=.92)$. The Cronbach’s alpha was .91.

Hedonistic/egoistic values was captured by five items about the importance of having fun and enjoying life, having a lot of free time, being rich and having a lot of money and things, looking good, freedom to do as I please. The items were followed by a 5-point scale ranging from 'not at all important (1)' to 'very important (5)' $(M=4.07, S D=.55)$. The scale was developed by Stattin and Kerr (2001) to fit an adolescent population. Cronbach’s alpha reliability was .64.

Inclination towards a conservative political orientation was captured by the stem question: ‘Do you like any of these political parties’ youth organizations?’ Eleven alternatives followed, of which this study concentrated on the youth organizations associated with the two largest conservative parties in Sweden: 'Moderaterna' and 'Sverigedemokraterna.' The answers were transformed into two dummy variables with 'liking = 1' and 'not liking or indifferent $=0{ }^{\prime}$

Tolerance toward immigrants was measured with a scale used in van Zalk and colleagues (2013). The stem question concerned the young people's view of people who have moved to Sweden from other countries, and was followed by the following four items: 'Our culture gets enriched when people from other countries move here,' 'In the future Sweden will be a country where there are exciting encounters between people from different parts of the world,' 'We should welcome people who have fled from the problems in their own countries,' 'Immigrants should have the same rights as people born in Sweden.' Each item was followed by the response alternatives: 'Doesn’t apply at all (1),' 'Doesn’t apply so well (2),' 'Applies quite well (3),' 'Applies very well (4)’ $(\mathrm{M}=2.93, \mathrm{SD}=.74)$. The Cronbach’s alpha of the scale was .83 . 
Trust in societal institutions was measured with a scale tapping people's support or lack of support for the following seven societal institutions: 'the parliament,' 'the government,' 'the courts,' 'the police,' 'political parties,' ‘the European union,' and 'social movements' (see Linde 2004 and Norris 1999). For each item the young people were asked to choose from the following alternatives: 'no trust at all (1),' 'not a lot of trust (2),' 'quite a lot of trust (3),' 'a lot of trust (4)’ $(\mathrm{M}=2.46, \mathrm{SD}=.67)$. The Cronbach’s alpha of the scale was .90.

Interest in political and societal issues was measured with a scale that has been found to correlate with pro-environmental actions in an earlier study (Ostman 2014). The scale was aggregated from three items where the youth first rated their feelings about politics on a scale ranging from 'hate it $=1$ ' to 'really enjoyable $=6$.' Thereafter they answered two questions on how interested they are in politics and how interested they are in societal issues. The questions were followed by a five-point scale ranging from 'not at all interested = 1,' through 'somewhat interested $=3$,' to 'very interested $=5$.' The three questions were z-transformed before being averaged into a composite scale $(\mathrm{M}=0, \mathrm{SD}=.88)$. Cronbach’s alpha was .86 .

Environmental efficacy was measured with two items developed for this study: 'I'm confident that I myself can do something to save the environment' and 'If we all pitch in we can solve many environmental problems' $(\mathrm{M}=3.62, \mathrm{SD}=1.01)$. The items were followed by the alternatives: 'Doesn’t apply at all = 1,' 'Doesn't apply so well = 2,' 'Kind of applies = 3,' ‘Applies quite well = 4,' ‘Applies perfectly = 5.' Cronbach’s alpha was .68.

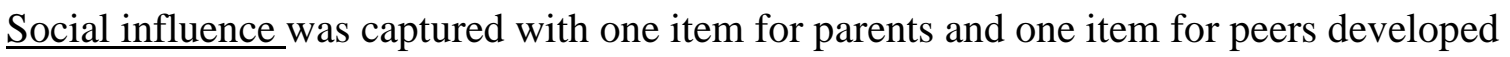
for this study: 'My parents believe that the problems concerning the environment and the climate change impact have been exaggerated' $(M=2.22, \mathrm{SD}=.78)$, 'My friends believe that the problems concerning the environment and the climate change impact have been exaggerated $(M=2.31, \mathrm{SD}=.78)$.' The items were followed by these alternatives: 'Doesn't apply at all (1),' 'Doesn’t apply so well (2),' 'Applies quite well (3),' 'Applies perfectly (4).' 


\section{Results}

\section{Which factors are related to climate skepticism cross-sectionally?}

First, correlation analyses were conducted between, on the one hand, climate change skepticism and, on the other hand, media use, subjective knowledge, environmental values, hedonistic/egoistic values, trust in institutions, interest in politics and societal issues, tolerance toward immigrants, environmental efficacy, and social influence from parents and peers at T1 (see Table 1). All the factors except media use were significantly correlated with climate change skepticism.

In Table 1 it can be seen that the likelihood of young people embracing climate skeptical attitudes is greater the less knowledge they perceive themselves as having, the less important they perceive environmental values to be, the less trust they have in institutions, the less interest they have in societal and political issues, the less environmental efficacy they feel, and the less tolerance they have toward immigrants. In addition, the more strongly they embrace hedonistic values and the more they perceive their parents and peers as harboring skepticism concerning climate change, the more likely they are to score high on the measure of climate change skepticism. At T1 climate skepticism has the strongest correlation with social influence from parents, closely followed by social influence from peers and environmental efficacy. Thereafter follow tolerance towards immigrants and environmental values.

Insert Table 1 about here

In order to find out if there are gender differences when it comes to climate skepticism and whether supporters of the youth organizations of the two largest conservative parties in 
Sweden are more inclined to embrace climate skeptical attitudes than non-supporters, three independent t-tests were performed (climate skepticism at T1). The analyses show that the young men $(\mathrm{M}=2.28)$ are more inclined to embrace climate skeptical attitudes than the young women $(\mathrm{M}=1.90), \mathrm{t}(-5.57)=\mathrm{p}<.001$. In addition, those who claim they sympathize with the youth branch of the conservative party 'Sverigedemokraterna' are more likely to be climate change skeptical $(M=2.50)$ than those who claim that they do not sympathize with the youth organization or who are indifferent $(\mathrm{M}=2.04), \mathrm{t}(-3.11)=, \mathrm{p}<.01$. There is, however, no significant tendency for those who sympathize with the youth organization of the conservative political party 'Moderaterna' to hold stronger skeptical attitudes towards the climate change issue $(M=2.13)$ than those who do not sympathize with or who are indifferent to this party $(\mathrm{M}=2.07), \mathrm{t}(-0.52)=\mathrm{p}=.606$ (n.s.).

\section{Which factors predict climate skepticism cross-sectionally?}

In order to determine their independent contributions, the factors that were significant in the bivariate analyses were included in a hierarchical multiple regression analysis (see Table 2). In the first step, the variables that have been found to relate to climate change skepticism among adults were entered; these were gender, subjective knowledge, environmental and hedonistic values, and a conservative political orientation (Sverigedemokraterna). Gender, subjective knowledge, a conservative orientation, and environmental values were significant independent predictors. In the second step the variables related to societal powerlessness were inserted into the model. Here, environmental values and a conservative political orientation lost their independent contribution, while gender and subjective knowledge remained significant independent predictors. In addition, environmental efficacy, trust in institutions, and tolerance toward immigrants had unique significant influences on climate change skepticism. 
Finally, in the third step it was tested whether influence from parents and peers can explain climate change skepticism over and above the factors described above. In Table 2 we can see that this is the case since influence from parents is the strongest predictor, closely followed by influence from friends. Other factors that were unique predictors of climate change skepticism were environmental efficacy, which was the third strongest predictor, tolerance toward immigrants, subjective knowledge, trust in institutions, and gender. The proportion of variance accounted for by the full model was $20 \%, F(11,637)=14.24$; p < .001 .

\section{Which factors at $\mathbf{T 1}$ are related to climate skeptical attitudes at T2?}

First, correlation analyses were conducted between, on the one hand, climate skepticism at T2 and, on the other hand, media use, subjective knowledge, environmental values, hedonistic/egoistic values, trust in institutions, interest in politics and societal issues, environmental efficacy, tolerance towards immigrants, and social influence from parents and peers at T1 (see Table 1). Again, all variables, except for media use, had significant correlations with climate skepticism.

In Table 1 one can see that the less knowledge the young people perceive themselves as having at T1, the less important they perceive environmental values to be at T1, the less trust they have in institutions at T1, the less interest they have in societal and political issues at T1, the less they feel environmental efficacy at T1, and the less tolerance they have towards immigrants at T1, the more likely they are to embrace climate skeptical attitudes one year later, at T2. Furthermore, the more strongly they embrace hedonistic values at $\mathrm{T} 1$ and the 
more they perceive their parents and peers as harboring skepticism concerning climate change at $\mathrm{T} 1$, the more likely they are to score high on the measure of climate change skepticism one year later, at T2. Again, the strongest relations are with social influence from parents, this time closely followed by tolerance toward immigrants and social influence from peers.

In order to find out whether there are gender differences in climate skepticism at T2 and whether those young people who harbor sympathies for the youth organizations of the two conservative parties 'Sverigedemokraterna' and 'Moderaterna' at T1 embrace climate skeptical attitudes at T2 to a significantly higher degree than those who do not, three independent t-tests were performed. The analyses show that the young men $(M=2.10)$ harbor significantly stronger climate skeptical attitudes at T2 than the young women $(\mathrm{M}=1.78)$, $\mathrm{t}(-$ 4.26) $=\mathrm{p}<.001$. Supporters of 'Sverigedemokraterna' at T1 scored higher on climate skepticism at T2 $(\mathrm{M}=2.18)$ than non-supporters $(\mathrm{M}=1.93)$, although this time the difference was not significant, $\mathrm{t}(-1.62)=\mathrm{p}=.106$ (n.s.). In addition there was no significant difference between supporters $(\mathrm{M}=2.09)$ and non-supporters $(\mathrm{M}=1.93)$ of 'Moderaterna' at $\mathrm{T} 1 \mathrm{when}$ it comes to climate skepticism at $\mathrm{T} 2, \mathrm{t}(-1.25)=\mathrm{p}=.211$ (n.s.).

\section{Which factors predict climate skeptical attitudes over one year?}

Because levels of climate skepticism at T2 are likely to be explained to a certain degree by climate skeptical attitudes at T1 (baseline level), climate skepticism at T1 was included as a control variable in the first step of a hierarchical regression analysis. This makes it possible to interpret the results of the regression analysis as the impact of the other independent variables on the change in climate skepticism over one year, given the initial level of this variable. In addition, the researcher also can find out how much of the variance in climate skepticism at T2 that is explained by skepticism at T1, i.e., the stability in these attitudes over time can be captured. Only factors significant in the bivariate analyses were included in the analysis. 
Not surprisingly, climate skeptical attitudes at T1 predicted climate skeptical attitudes at T2 (see Table 3). At T2, 32\% of the variance in climate change skepticism was explained by climate skeptical attitudes at T1, indicating a rather large degree of stability in these attitudes over time. When it comes to the other independent variables, the environmental values factor was found to be a significant independent predictor in step two of the model; however, in step three, when the variables related to powerlessness were inserted, this independent effect disappeared. In step three the only other predictor with a significant unique effect was tolerance toward immigrants. This variable was also a significant independent predictor in the last step of the model, as was influence from parents. Hence, tolerance toward immigrants predicted a small significant reduction in climate skeptical attitudes, and perceived parental climate skeptical attitudes predicted a small significant increase in climate skeptical attitudes over this one-year period. The full model accounted for $35 \%$ of the variance, $F(11,593)=$ $28.65 ; \mathrm{p}<.001$.

Insert Table 3 about here

\section{Discussion}

This study has shown that many factors that have been found to predict climate change skepticism among adults in cross-sectional analyses, such as values, political orientation, knowledge, and gender, also explained climate skeptical views among adolescents living in Sweden. In addition, trust in societal institutions, environmental efficacy, tolerance toward immigrants, and social influence from parents and peers also seem to matter to the young. In addition, the longitudinal analysis indicates that climate skepticism is quite stable over a oneyear period. When it comes to explaining the rather small change that took place in climate skepticism over one year, only tolerance toward immigrants and perceived climate skeptical 
views held by one’s parents, i.e., descriptive social norms, had unique significant, albeit small, influences.

\section{Knowledge and values as predictors}

That less subjective knowledge concerning climate change and other societal issues went together with climate skepticism in this study supports results of earlier studies (Engels, et al. 2013; Ojala 2013). Although perceived knowledge was not the most important predictor cross-sectionally and did not have a unique influence over time, these results indicate that better and/or more education about climate change could to some extent counteract climate skepticism among the young.

Environmental values and hedonistic values were also found to have associations with climate skepticism both cross-sectionally and over a one-year period. This accords with studies conducted on adults (Engels et al. 2013; Islam et al. 2013; Leiserowitz et al. 2013; Poortinga et al. 2011; Whitmarsh 2011) and theories such as identity protective theory (Kahan et al. 2007) that claim people judge risks in accordance with their cultural worldviews. In this case this means that young people were inclined to have less climate skeptical views if they thought environmental values were important, and stronger climate skeptical views if they embraced hedonistic values to a higher degree. Thus when it comes to young people who do not think that environmental values are important and/or who embrace hedonistic values to a high degree, in order to reach them, educators could emphasize positive side effects of fighting climate change, side effects that are more compatible with these young people's values, for instance, economic development and public health. This approach has been found to be effective among adults (Bain et al. 2012).

Still, it should be noted that the unique significant effect of environmental values disappeared when the more proximal variables related to perceived societal powerlessness and social influence were inserted into the two regression analyses. That environmental values and 
climate change attitudes among parents and friends are closely interrelated is perhaps not so surprising and will be discussed below in the section about social influence. Furthermore, that there are associations between societal powerlessness and views on environmental issues will be discussed in the immediately following section.

\section{Societal powerlessness and climate change skepticism}

This study also showed that many factors related to societal powerlessness—distrust in institutions, low interest in societal issues, and a feeling that you cannot personally influence environmental issues - were related to climate skepticism in bivariate analyses and the multiple regression analysis in the cross-sectional part of the study, as well as in longitudinal bivariate analyses. These results are in contrast to theories and studies among adults claiming that people with a great deal of power in society defend their position of power by denying climate change (Fegynia et al. 2010, McCright \& Dunlap 2011). These results accord instead with Skogen's (1999; Strandbu and Skogen 2000) studies showing that young people with less power in society are also less environmentally interested. They are also in line with research linking a low environmental interest and climate skepticism to low trust, low interest in societal issues and low environmental efficacy (Ojala 2012b, 2013; Engels et al. 2013; Harring and Jaegers 2013; Hobson and Niemeyer 2013).

A possible explanation for these results could perhaps be found in a recent Swedish study on adults showing that a group with less power in society, people with lower education, were more inclined to perceive the climate change problem as exaggerated (Knez, Thorsson and Eliasson 2013). At the same time these people were more likely to perceive their jobs to be threatened by stricter environmental laws and protection than those with higher education, results that also were the case when comparing men with women. These results related to societal powerlessness point to the importance of not only focusing on scientific knowledge in a traditional manner in climate change education, but also aiming to increase young people's 
action competence (Jensen and Schnack 1997). Action competence concerns aspects such as discussing different possibilities for solving societal and environmental problems, working with visions of the future and with motivation, and giving the students action experiences.

\section{The importance of tolerance}

In addition, tolerance toward immigrants explained climate skepticism cross-sectionally in this study, and also had a unique significant influence, although quite a small one, on change in climate skeptical views over one year. The lower degree of tolerance toward immigrants the young people had at T1, the more likely they were to increase their climate skeptical views by T2, and the higher degree of tolerance they had at T1, the more likely they were to decrease their climate skeptical views over this one-year period.

What underlying factors can explain these results? Research has shown that low tolerance toward immigrants is related to both distrust concerning societal issues (Hjerm 2006) and a conservative political orientation (Pettigrew 1998). However, because these factors were controlled for in the regression analyses, something else must explain the associations found with climate change skepticism. Van Zalk and colleagues (2013) argue that tolerance toward immigrants is based on an advanced abstract understanding of equality between different groups of people, and this kind of thinking is not well developed among all young people, nor among all adults. Other researchers have found that anti-immigrant attitudes are closely related to an inability to harbor uncertainty (Wichman 2012). These results are interesting to consider in relation to global climate change, because the latter problem demands both a capacity for abstract thinking and the ability to face scientific uncertainty without denying altogether that the problem exists. Thus, measures of abstract thinking and tolerance of uncertainty should be included in future studies that explore climate change skepticism among young people. Still, because this study has demonstrated a significant relation between climate skeptical attitudes and low tolerance toward immigrants among young people, lessons 
learned from general programs to fight anti-immigrant attitudes could perhaps also be useful for critically discussing climate skeptical views in school.

\section{Parents as important socialization agents}

Besides tolerance toward immigrants, perceived climate skeptical views held by one’s parents also had significant associations with climate skeptical attitudes cross-sectionally as well as longitudinally and explained a small but significant change in climate change skepticism over the one-year period. Descriptive social norms concerning parents, together with descriptive social norms in relation to friends, were also the most important predictors of climate change skepticism cross-sectionally. Studies of the socialization of young people's environmental orientations have found that parents’ pro-environmental values, attitudes, and actions are positively correlated with their teenagers' values, attitudes, and actions concerning the environment (Grönhöj and Thøgersen 2009; Leppänen et al. 2012). This study extends these results to concern a negative orientation toward one of the most important environmental problems, namely climate change.

It is also interesting to note that parents were more important socialization agents than friends when it comes to climate change skepticism. Perhaps the climate change issue is not discussed extensively with friends, and instead young people get their views through discussions in the family. Although social influence from friends generally increases in the teenage years, some studies show that parents are still the most importance influence on adolescents when it comes to societal issues (Dostie-Goulet 2009). Furthermore, the finding that descriptive social norms were more important than values in predicting climate skepticism might have to do with the fact that values and political orientations are not yet wholly internalized when it comes to young people. This further emphasizes the importance of not only including scientific facts in climate change education among this age-group but 
also of training young people in skills vital for becoming active democratic citizens, such as how to think critically about predetermined social norms (see Wals 2010).

\section{Strengths and limitations}

This study has some limitations that need to be mentioned. The associations between climate change skepticism and the different factors were not particularly strong, and the explained variance in change in climate skeptical attitudes over one year was small. This could be due to the fact that the time interval between the two waves was too short to capture change influenced by the independent factors. However, the identified stability in climate skeptical attitudes over this one-year period can also be seen as a main strength of the study. To a certain degree it challenges the view of children and adolescents as unreliable subjects to include in survey studies as they are seen for instance as changing views on different issues in an erratic manner (for a critique of this view see Scott, 2000). The study instead indicates that climate change skepticism is a rather stable construct. Furthermore, that the correlations between skepticism at $\mathrm{T} 1$ and the other factors are about the same at $\mathrm{T} 1$ and $\mathrm{T} 2$ indicates that the reliability of the included scales is high.

Another weakness is that the participants who dropped out of the study from T1 to T2 scored significantly higher on influence from parents than those who participated at both time points, thus, results concerning 'perceived climate skeptical views of one’s parents' should be interpreted with this in mind, i.e., most probably the positive relations over time with climate skepticism would have been stronger if these persons had remained in the study. Many of the identified significant relations are, however, in accordance with findings of earlier studies on adults and are in line with theoretical accounts. In addition, some of the predictors in this study were captured with single-item measures, which are often seen as less reliable than multi-item scales. However, studies have shown that they can be as accurate as multi-item measures (Wanous and Hudy 2001; Wanous, Reichers and Hudy 1997). Finally, although 
many of the findings are in line with results from studies performed on adults in different countries, one should bear in mind that this study only focuses on young people living in Sweden. More studies are needed in other countries to investigate whether the factors identified are also important among young people living outside Sweden.

Some strengths of the present study should also be mentioned. It is the first study to explore possible predictors of climate skepticism among young people, and one of few that have explored this concept in a longitudinal context. The longitudinal design made it possible to predict change in climate skeptical views over one year, to investigate stability in the results, and to shed some light on issues of causality (Lynn, 2009). Although it is not certain that the climate skeptical views will remain stable among the young people as they grow older, it is still of the utmost importance to find out which factors are important in explaining climate change skepticism among this age group, because this is the age when people get much of their understanding of climate change in school, and it is also the age when social norms are internalized into values. Thus, the explanatory factors identified in this study are important to take account of in climate change education. 


\section{References}

Abdelzadeh, A., and J. Ekman. 2012. 'Understanding critical citizenship and other forms of public dissatisfaction: An alternative framework.’ Politics, culture and socialization 3(1): 177-194.

Antilla, T., K. Poikolainen, A., Uutela, A., J. Lonnqvist. 2000 'Structure and determinants of worrying among adolescent girls.' Journal of Youth Studies 3(1): 49-60.

Amnå, E., M. Ekström, M. Kerr, and H. Stattin. 2009.'Political socialization and human Agency: The development of civic engagement from adolescence to adulthood.' Statsvetenskaplig tidskrift 111(1): 27-39.

Bain, P.G, M.J. Hornsey, R. Bongiorno, and C. Jeffries. 2012. 'Promoting pro-environmental action in climate change deniers.' Nature Climate Change 2: 600-603.

Bandura, A. 1977. Social Learning Theory. New York: General Learning Press.

Biel, A., N. Fransson, U. Dahlstrand. 1997. 'Moral values assigned to real-life events.' Scandinavian Journal of Psychology 38: 21-28.

Boykoff, M.T., and J.M. Boykoff. 2004. 'Balance as bias: Global warming and the US prestige press.' Global Environmental Change 14: 125-136.

Brysse, K., N. Oreskes, J. O’Reilly, and M. Oppenheimer. 2013. 'Climate change prediction: Erring on the side of least drama?' Global Environmental Change 23: 327-337.

Bynner, J.M., D.M. Romney, and N.P. Emler. 2003. 'Dimensions of political and related facets of identity in late adolescence.' Journal of Youth Studies 6(3): 319-335.

Carlsson-Kanyama. A., and L. Hörnsten Friberg. 2012. Views on climate change and adaptation among politicians and directors in Swedish municipalities. Report from Naturvårdsverket, Sweden.

Cialdini, R. B. 2007. 'Descriptive social norms are underappreciated sources of social 
control.’ Psychometrica 72(2): 263-268.

Davidson, D.J. and M. Haan. 2012. 'Gender, political ideology, and climate change beliefs in an extractive industry community.' Population and Environment 34(2): 217-234.

Dostie-Goulet, E. 2009. 'Social Networks and the Development of Political Interest.' Journal of Youth Studies 12: 405-421.

Engels, A., O. Hüther, M. Schäfer, and H. Held. 2013. 'Public climate-change skepticism, energy preference and political participation.' Global Environmental Change 23(5): 1018-1027.

Eurobarometer 2009. Europeans' attitudes towards climate change.

Retrieved 18 August, from: http://ec.europa.eu/sverige/documents/

eurobarometer_klimatforandringar.pdf

Feygina, I., J.T. Jost, and R.E. Goldsmith. 2010. 'System justification, the denial of global warming, and the possibility of 'System-sanctioned change'.' Personality and Social Psychology Bulletin 36: 326-338.

Gordon, H.R., and J.K. Taft. 2011. 'Rethinking youth political socialization: Teenage activists talk back.’ Youth \& Society 43(4): 1499-1527.

de Groot, J.I.M., and L. Steg. 2008. ‘Value Orientations to Explain Beliefs Related to Environmental Significant Behavior: How to Measure Egoistic, Altruistic, and Biospheric Value Orientations.' Environment and Behavior 40: 330-354.

Grønhøj, A., and J. Thøgersen. 2009. 'Like father, like son? Intergenerational transmission of values, attitudes, and behaviours in the environmental domain.' Journal of Environmental Psychology 29: 414-421.

Harring, N., and S.C. Jagers. 2013. 'Should we trust in values? Explaining public support for pro-environmental taxes.' Sustainability 5: 210-227.

Hjerm, M. 2006. 'What the future may bring: Xenophobia among Swedish adolescents.' 
Acta Sociologica 48(4): 292-307.

Hobson, K., and S. Niemeyer. (2013). '”What sceptics believe”': The effects of information and deliberation on climate change scepticism.' Public Understanding of Science, in press.

Holmberg, S. 2007. ‘Sverigedemokraterna, vilka är dom och vad vill dom?’ In Det nya Sverige, edited by S. Homberg, and L. Weibull, 11-36. Gothenburg: SOM. Göteborgs Universitet.

Holmberg, S., L. Weibull, and H. Oscarsson. 2011. Lycksalighetens ö. Gothenburg: SOMReport 52.

IPCC 2007. Climate change 2007: synthesis report. Summary for Policymakers. Geneva, Switzerland: IPCC.

IPCC 2013. Climate change 2013: The physical science basis. Summary for policymakers. Switzerland: IPCC.

Islam, M., A. Barnes, and L. Toma. 2013. 'An investigation into climate scepticism among farmers.’ Journal of Environmental Psychology 34: 137-150.

Jackman, S. 2009. Australians, Americans and climate change. Sydney: The United States studies center. University of Sydney.

Jensen, B.B., and K. Schnack. 1997. 'The action competence approach in environmental education.' Environmental Education Research 3(2): 163-178.

Kahan, D.M., D. Braman, J. Gastil, P. Slovic, and C.K. Mertz. 2007. 'Culture and identityprotective cognition: Explaining the white male effect in risk perception.' Journal of Empirical Legal Studies 4(3): 465-505.

Kahan, D.M., E. Peters, M. Wittlin, P. Slovic, L. Larrimore Ouellette, D. Braman, and G. Mandel. 2012. 'The polarizing impact of science literacy and numeracy on perceived climate change risks.’ Nature Climate Change 2: 732-735. 
Klöckner, C.A., A. Beisenkamp, and S. Hallmann. 2010. ,Klimawandel aus der Sicht 9-14 jährige Kinder-Emotionen, Bewältigungressourcen und allgemeines Wohlbefinden.` Umweltpsychology 14: 121-142.

Knez, I., S. Thorsson, and I. Eliasson. 2013. 'Climate Change: Concerns, beliefs, and emotions in residents, experts, decision makers, tourism, and tourism industry.' American Journal of Climate Change 2: 254-269.

Leiserowitz, A.A., E.W. Maibach, C. Roser-Renouf, N. Smith, and E. Dawson. 2013. ,Climategate, public opinion, and the loss of trust.' American Behavioral Scientist 57: 819-837.

Leppänen, J.M., A.E. Haala, A.M. Lensu, and M.T. Kuitunen. 2012. 'Parent-Child Similarity in Environmental Attitudes: A Pairwise Comparison.' Journal of Environmental Education 43(3): 162-176.

Leviston, Z, and I. Walker. 2012. 'Beliefs and Denials about climate change: An Australian perspective.’ Ecopsychology 4(4): 277-285.

Linde, J. 2004. 'Doubting Democrats? A Comparative Analysis of Support for Democracy in Central and Eastern Europe.’ PhD diss., Örebro Studies in Political Science 10. Örebro University.

Livingstone, S., and T. Markham. 2008. 'The contribution of media consumption to civic participation.’ British journal of sociology 59(2): 351-371.

Lynn, P. 2009. 'Methods for longitudinal surveys.’ In Methodology of Longitudinal Surveys, edited by P. Lynn, 1-20. Hoboken, NJ: Wiley.

Lynn Guber, D. 2013. 'A cooling climate for change? Party polarization and the politics of global warming.' American Behavioral Scientist 57(1): 93-115. 
Maccoby, E. 2007. 'Historical overview of socialization research and theory.' In Handbook of socialization: Theory and Research, edited by J.E. Grusec, and P.D. Hastings, 13-41. New York: Guildford.

McCright, A.M., and R.E. Dunlap. 2011. 'Cole dudes: The denial of climate change among conservative white males in the United States.' Global Environmental Chang, 21: 11631172.

Nolan, J., P.W. Schultz, R.B. Cialdini, V. Griskevicius, and N. Goldstein. 2008. 'Normative social influence is underdetected.’ Personality and Social Psychology Bulletin 34: 913923.

Norris, P. (Ed.). 1999. Critical citizens: global support for democratic government. Oxford: Oxford University Press.

Ojala, M. 2005. 'Adolescents' worries about environmental risks: subjective well-being, values, and existential dimensions.' Journal of Youth Studies 8(3): 331-348.

Ojala, M. 2012a. 'Hope and climate change: The importance of hope for pro-environmental engagement among young people.’ Environmental Education Research 18(5): 625-642.

Ojala, M. 2012b. 'How do children cope with global climate change? Coping strategies, engagement, and well-being.' Journal of Environmental Psychology 32: 225-233.

Ojala, M. 2012c. 'Regulating worry, promoting hope: How do children, adolescents, and young adults cope with climate change?’ International Journal of Environmental and Science Education 7(4): 537-561.

Ojala, M. 2013. 'Coping with climate change among adolescents: Implications for subjective well-being and environmental engagement.' Sustainability 5(5): 2191-2209. 
Oscarsson, H., and S. Homberg. 2008. Regeringsskifte: väljarna och valet 2006. Sweden: Nordstedt Juridik.

Ostman, J. 2014. 'The influence of media use on environmental engagement: A political socialization approach.’ Environmental Communication 8(1): 92-109.

Pettigrew, T.F. 1998. 'Reactions towards the new minorities of Western Europe.' Annual Review of Sociology 24: 77-103.

Poortinga, W., A. Spence, L. Whitmarsh, S. Capstick., and N.F. Pidgeon. 2011. ‘Uncertain climate: An investigation into public skepticism about anthropogenic climate change.’ Global Environmental Change 21(3): 1015-1024.

Rahmstorf, S. 2004. The climate sceptics. Potsdam Institute for Climate Impact Research, Potsdam. Retrieved at 13 January, at: http://www.pikpotsdam.de/ stefan/Publications/Other/rahmstorf_climate_sceptics_2004.pdf Royal Society 2010. Climate change: a summary of the science. London: Royal Society. Scott, J. 2000. 'Children as respondents: The challenge for quantitative methods.' In Research with Children, edited by P. Christensen and A. James, 98-119. London: Routledge.

Schwartz, S. H. 1977. 'Normative influences on altruism.’ In Advances in experimental social psychology, Volume 10, edited by L. Berkowitz, 221- 279. New York: Academic Press.

Skogen, K. 1999. 'Another look at culture and nature: How culture patterns influence environmental orientation among Norwegian youth.’ Acta Sociologica 42: 223-239. Smith, N., and A. Leiserowitz. 2012. 'The rise of global warming skepticism: Exploring affective image associations in the United States over time.' Risk Analysis 32: 1021-1031. Statistics Sweden 2010. Population statistics. Örebro: Sweden statistics. At www. scb.se 
Skogen, K., and Å. Strandbu. 2000. 'Environmentalism among Norwegian Youth: Different Paths to Attitudes and Action?' Journal of Youth Studies 3(2): 189-209.

Stattin, H, and M. Kerr. 2001. 'Adolescents’ Values Matter.’ In Navigating Through Adolescence: European Perspectives, edited by J.-E. Nurmi, 21-58. New York: Routledge.

Thøgersen, J.B. 2006. 'Norms for environmentally responsible behavior: An extended taxonomy.' Journal of Environmental Psychology 26: 247-261.

Van Zalk. M.H., M. Kerr, N. van Zalk, and H. Stattin. 2013.’ Xenophobia and tolerance toward immigrants in adolecence: Cross-influence processes within friendships.' Journal of Abnormal Child Psychology 41: 627-639.

Wals, A. E. J. 2010. 'Mirroring, Gestaltswitching and transformative social learning.' International Journal of Sustainability in Higher Education 11 (4): 380-390.

Wanous, J.P., and M.J. Hudy. 2001. 'Single-item reliability: A replication and extension.' Organizational Research Methods 4: 361-75.

Wanous, J.P., A.E. Reichers, and M.J. Hudy. 1997. 'Overall job satisfaction: How good are single-item measures?' Journal of Applied Psychology 82: 247-52.

Whitmarsh, L. 2011. 'Scepticism and uncertainty about climate change: Dimension, determinants and change over time.' Global Environmental Change 21: 690-700.

Wichman, A.L. 2012. 'Uncertainty threat can cause stereotyping: The moderating role of personal need for structure.' SAGE Open 2: 1-7.

Wilson, S.J, and C. Snell 2010. 'Bad for the penguins ... because they need ice and that to live on': an exploratory study into the environmental views, concerns and knowledge of socially disadvantaged young people.' Journal of Youth Studies 13(2): 151-168. 
Table 1

Pearson correlations between, on the one hand, climate change skepticism at T1 and T2, and, on the other hand, subjective knowledge, media use, environmental values, hedonistic values, trust in institutions, interest in societal issues, environmental efficacy, tolerance toward immigrants, influence from parents, and influence from peers at T1.

\begin{tabular}{|l|l|l|}
\hline & \multicolumn{2}{l|}{ Climate change skepticism } \\
\hline T1 & T1 & T2 \\
\hline Subjective knowledge & $-.11^{* *}$ & $-.11^{* *}$ \\
\hline Media use & .01 & .00 \\
\hline Environmental values & $-.19^{* * *}$ & $-.17^{* * *}$ \\
\hline Hedonistic values & $.09^{* *}$ & $.09^{*}$ \\
\hline Trust in institutions & $-.19^{* * *}$ & $-.16^{* * *}$ \\
\hline Interest in societal issues & $-.12^{* * *}$ & $-.14^{* * *}$ \\
\hline Environmental efficacy & $-.26^{* * *}$ & $-.24^{* * *}$ \\
\hline Tolerance immigrant & $-.23^{* * *}$ & $-.21^{* * *}$ \\
\hline Influence from parents & $.30^{* * *}$ & $.26^{* * *}$ \\
\hline Influence from peers & $.26^{* * *}$ & $.20^{* * *}$ \\
\hline
\end{tabular}

Note. ${ }^{*} \mathrm{p}<=.05 ;{ }^{* *} \mathrm{p}<=.01 ; * * * \mathrm{p}<=.001$ 
Table 2

Hierarchical multiple regression analysis predicting climate change skepticism at T1

\begin{tabular}{|c|c|c|c|}
\hline & \multicolumn{3}{|c|}{ Climate change skepticism at T1 } \\
\hline & $\begin{array}{c}\text { Step } 1 \\
\beta\end{array}$ & $\begin{array}{c}\text { Step } 2 \\
\beta\end{array}$ & $\begin{array}{c}\text { Step } 3 \\
\beta\end{array}$ \\
\hline Gender (girl = 0; boy $=1$ ) & $.16^{* * *}$ & $.11 * *$ & $.09 *$ \\
\hline Subjective knowledge & $-.13 * * *$ & $-.10 *$ & $-.11^{*}$ \\
\hline Conservative orientation & $.09 *$ & .06 & .04 \\
\hline Environmental values & $-.13 * * *$ & -.06 & -.02 \\
\hline Hedonistic values & .04 & .02 & .01 \\
\hline Trust in institutions & & $-.10 *$ & $-.10 *$ \\
\hline Interest in societal issues & & .08 & .09 \\
\hline Environmental efficacy & & $-.12 * *$ & $-.12 *$ \\
\hline Tolerance immigrants & & $-.12 * *$ & $-11 * *$ \\
\hline Influence from parents & & & $.17 * * *$ \\
\hline Influence from peers & & & $.16^{* * *}$ \\
\hline $\mathbf{R}^{2}$ & $.08 * * *$ & $.12 * * *$ & $.20 * * *$ \\
\hline
\end{tabular}

Note. ${ }^{*} \mathrm{p}<=.05 ; * * \mathrm{p}<=.01 ; * * * \mathrm{p}<=.001$ 
Table 3

Hierarchical multiple regression analysis predicting climate change skepticism at T2

\begin{tabular}{|c|c|c|c|c|}
\hline & \multicolumn{4}{|c|}{ Climate change skepticism at T2 } \\
\hline & $\begin{array}{c}\text { Step } 1 \\
\quad \beta\end{array}$ & $\begin{array}{c}\text { Step } 2 \\
\beta\end{array}$ & $\begin{array}{c}\text { Step } 3 \\
\beta\end{array}$ & $\begin{array}{c}\text { Step } 4 \\
\beta\end{array}$ \\
\hline Climate change skepticism at $\mathrm{T} 1$ & $.56 * * *$ & $.54 * * *$ & $.52 * * *$ & $.50 * * *$ \\
\hline Gender $($ women $=0 ;$ men $=1)$ & & .07 & .05 & .04 \\
\hline Subjective knowledge & & -.01 & .03 & .02 \\
\hline Environmental values & & $-.08 *$ & -.05 & -.04 \\
\hline Hedonistic values & & -.01 & -.04 & -.04 \\
\hline Trust in institutions & & & .01 & .01 \\
\hline Interest in societal issues & & & -.05 & -.04 \\
\hline Environmental efficacy & & & -.05 & -.05 \\
\hline Tolerance immigrants & & & $-.08 *$ & $-.08 *$ \\
\hline Influence from parents & & & & $.08^{*}$ \\
\hline Influence from peers & & & & .02 \\
\hline $\mathbf{R}^{2}$ & $32 * * *$ & $33 * * *$ & $.34 * * *$ & $.35 * * *$ \\
\hline
\end{tabular}

Note. ${ }^{*} \mathrm{p}<=.05 ; * * \mathrm{p}<=.01 ; * * * \mathrm{p}<=.001$ 